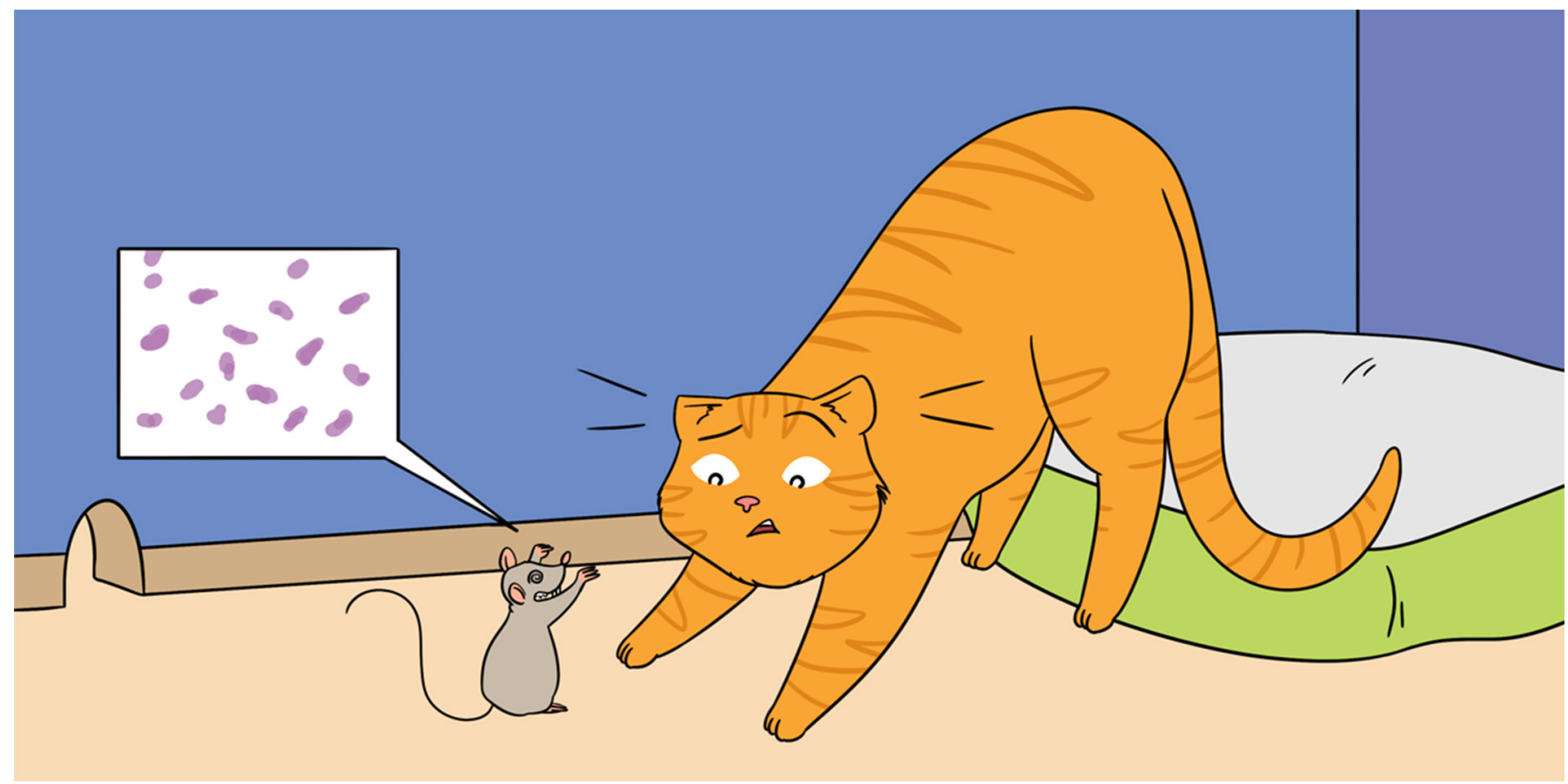

\title{
Toxoplasma gondii: A MICROBE THAT TURNS MICE INTO ZOMBIES
}

\section{Flávia Costa Mendonça-Natividade and Rafael Ricci-Azevedo *}

Laboratory of Immunochemistry and Glycobiology, Department of Cell and Molecular Biology and Pathogenic Bioagents, Ribeirão Preto Medical School, University of São Paulo (FMRP/USP), Ribeirão Preto, Brazil

YOUNG REVIEWERS:

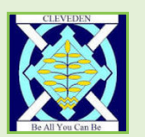

CLEVEDEN SECONDARY

AGE: 15

\section{PARASITE}

Any organism that lives in or on another organism without benefiting the host organism; usually refers to pathogens; most commonly, it concerns to protozoans and helminths.
Did you know that there is a microbe capable of turning mice into zombies? It sounds like a myth, does it not? But it is real! The name of this microbe is Toxoplasma gondii, and it is a parasite with the ability to infect a broad range of animals, including humans, and thrive in their muscles, eyes, and brains. T. gondii can change the behavior of the animal whose brain it has infected and can cause mice to lose their fear of being eaten by cats. In this article, you will get to know a little more about this parasite and how it turns mice into zombies!

\section{WHAT IS Toxoplasma gondii AND HOW DOES IT INFECT ANIMALS?}

T. gondii is a single-celled microbe around $6 \mu \mathrm{m}$ (micrometers, 1/1,000 of a millimeter) in size, which is $~ 550$ times smaller than an apple seed $(3.3 \mathrm{~mm})$ ! This organism is so tiny that we can only see it using the powerful lenses of a microscope. T. gondii only survives and multiplies when it infects a living cell, which is why it is classified as a parasite. 
HOST

In biology, a host is an organism that harbors another organism, typically providing with nourishment. The host can shelter a parasitic, a mutualistic, or a commensal "guest" (symbiont)

\section{OOCYST}

A hardy, thick-walled stage of the life cycle of some parasites. This is the stage in which the parasite is shed in the feces of infected animals.

\section{IMMUNE SYSTEM}

Also called natural defense mechanism, it is a complex network of interacting cells, cell products, and cell-forming tissues that protect the body from pathogens and other foreign substances.

TOXOPLASMOSIS

Is the parasitic disease caused by

Toxoplasma gondii.

\section{AMYGDALA}

Is a tiny almond-shaped cell mass located deep and medially within the temporal lobes of the brain in complex vertebrates. It is the brain region responsible for the processing of memory, decision-making, and emotional responses (including fear, anxiety, and aggression).
The animals that parasites infect are called hosts, and parasites often have complex life cycles that involve different shapes of the parasite and multiple hosts.

The life cycle of T. gondii is shown in Figure 1. Cats are one of the hosts of T. gondii, and they are the only host in which this parasite produces structures called oocysts. An oocyst is a thick-walled structure in which the parasite can survive for a long time outside a host. When cats are infected, they release the parasites' oocysts into the environment through their feces (poop). When other animals, such as birds, mice, cows, or even humans, ingest water, vegetables, or meat contaminated with oocysts, these animals can become infected. Once inside a new host, the parasites emerge from the oocysts and multiply. Now begins the fight between the parasite and the hosts' immune system. After invading a host cell, T. gondii tries to protect itself against attacks by the host's immune system by forming a bubble-like compartment inside the host cell. Inside this compartment, the parasite multiplies many times, enough to fill the entire cell, to the point of exploding the host cell! These parasites are now free to infect new cells in the host. This cycle then repeats itself. The cycle of parasite replication is what causes the disease known as toxoplasmosis.

Meanwhile, the immune system of the infected animal fights to kill $T$. gondii or at least block its multiplication. So, to avoid the attack coming from the host's defense mechanism, the parasites frequently turn into a sleeping form, lying dormant in the muscles, eyes, and brains of the infected animals. The parasites might sleep forever, without causing any damage, if the host's immune system is working well.

\section{WHAT HAPPENS WHEN T. gondii GETS INTO THE BRAIN?}

But, how do cats get infected with T. gondii in the first place? Well, as everybody knows, cats like to hunt and to eat mice. If a cat eats a mouse infected with T. gondii, the cat will become infected. Here is where things get even more interesting. We mentioned that T. gondii can infect a host's brain. The brain controls all the vital functions of an animal, so if parasites take up residence in the brain, it can be harmful. Let us find out what may happen if a mouse's brain is infected with $T$. gondii. Mice are normally afraid of cats, because cats are predators that present a constant, mortal threat to mice. However, when the brains of mice are infected with $T$. gondii, they lose their fear of cats, and can easily stare them in the face. Thus, the parasite seems to turn mice into fearless zombies! Is not that crazy? Mice lose their fear of cats and risk being eaten by them! This happens because, once the parasite is inside a mouse's brain, it may disrupt brain cell communication in a brain area called the amygdala, which is responsible for the feeling of fear [1]. Although this is a tragic situation for mice, it is perfect for $T$. 
Figure 1

Toxoplasma gondii life cycle-The definitive hosts for Toxoplasma gondii are the Felidae (domestic cats and their relatives). T. gondii oocysts are shed in the cats' feces.

Intermediate hosts

(birds, mammals,

including animals bred for human

consumption, and humans themselves) often become infected due to environmental factors, such as eating soil, water, or vegetables contaminated with oocysts. After being ingested, parasites spread themselves into neural and muscle tissue. Usually, the host immune system is working well and these parasites develop into tissue cysts, which is the dormant form of $T$. gondii. New cats become infected by the direct ingestion of environmental oocysts, or by consuming intermediate hosts harboring tissue cysts, such as mice. Interestingly, if mice are infected by the parasite, they lose their fear of being eaten by cats. It looks like the mice turn into zombies due to the T. gondii infection, which makes them easy prey for the cats.

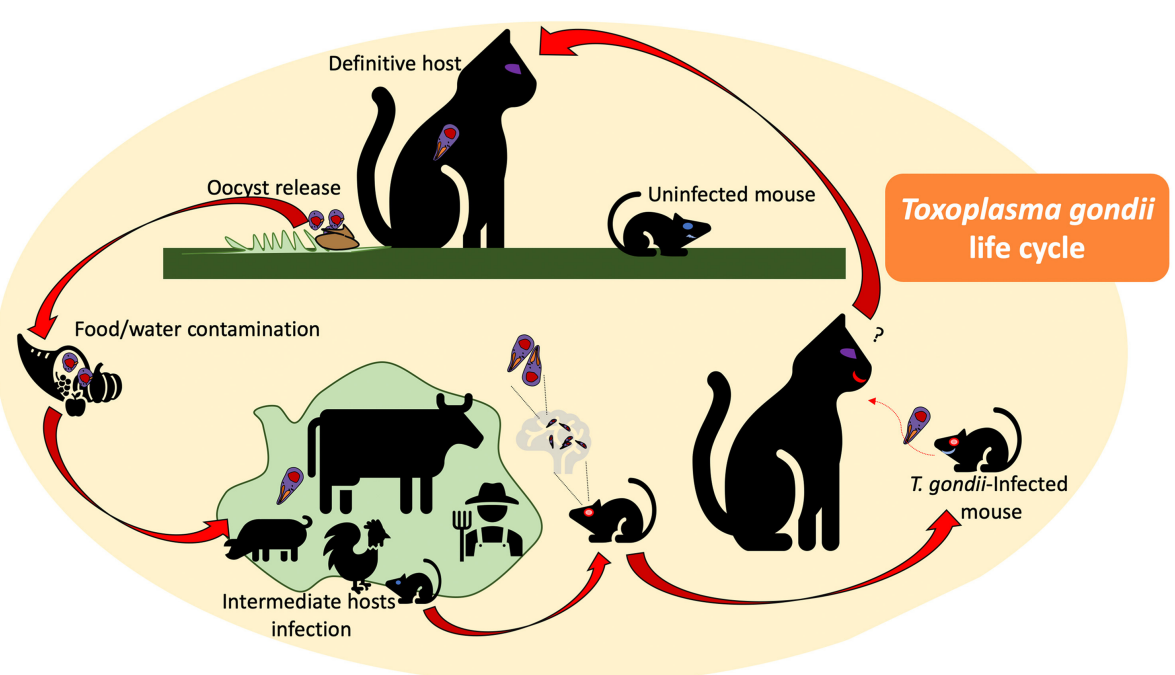

Figure 1

gondii, since infected mice will be more likely to get eaten by cats, which helps the parasite to reproduce!

\section{CAN HUMANS BE INFECTED WITH T, gondii?}

We told you that $T$. gondii can infect mammals, and humans are mammals... so could our cells be infected by this parasite too? The answer is yes! It has been found that $30-50 \%$ of the global population is infected with T. gondii [2]. It is also estimated that $50-80 \%$ of Brazilians are infected and already have symptoms of toxoplasmosis [3]. Usually, healthy people who are infected with T. gondii have no symptoms, because their immune systems keep the parasite from causing toxoplasmosis. When infected people do have symptoms, they are generally flu-like, such as muscle pain, fever and headache. These symptoms can last for weeks to months and then go away. However, the parasite remains in the body in an inactive state, even after symptoms are completely gone. If the person's immune system becomes suppressed at some point, the parasites can be reactivated and are able to infect other cells and multiply. Once awake, parasites can cause severe damage to the eyes and the brain. Also, if a pregnant woman becomes infected, the parasites can be transmitted to the fetus and cause malformations.

Can T. gondii affect the brains of humans like it does in mice? Several interesting facts suggest that this parasite can affect humans when it enters their brains. Scientists have described that, in people without a history of mental illness, T. gondii can cause abnormal behavior. They found a correlation between T. gondii infection and self-directed violence, including suicide [4]. Another study showed that students with toxoplasmosis were more likely to be businessmen, due to the lack of "fear of failure," than those who were not infected by the 
parasite [5]. Although these findings are interesting, further research is needed to understand the mental and psychological consequences of being infected by this parasite.

\section{HOW CAN WE PROTECT OURSELVES FROM TOXOPLASMOSIS?}

Unfortunately, there is currently no vaccine for toxoplasmosis. However, many researchers around the world are studying T. gondii, looking for an effective vaccine against this parasite [6, 7]. Also, it is important to keep in mind that once the hosts are infected, they will never be completely rid of $T$. gondii. The drugs used to fight this parasite do not destroy the dormant parasites. If the host's immune system ever becomes weak, these sleeping parasites may wake up and cause the typical symptoms of toxoplasmosis. That is why it is so essential to avoid getting infected by T. gondii in the first place. Infection can happen if you ingest water or food contaminated with cat feces. But your cat is not the one to blame, so do not abandon your pet. Cats usually hide their feces in sand or soil, so the infection commonly happens due to environmental factors. Therefore, here are some tips to avoid being infected by this parasite:

(1) Properly dispose of the waste from the cat litter box.

(2) Wash your hands thoroughly after playing in the sand or handling soil, especially before meals.

(3) Properly clean all fruits and vegetables before cooking or eating.

(4) Wash kitchen utensils thoroughly.

(5) Drink water or other beverages only if filtered or if they are from reliable sources.

(6) Do not eat undercooked meat or feed it to your pet.

In this article, we told you about how toxoplasmosis occurs, and some unpleasant effects triggered by infection with $T$. gondii. In addition, we told you about a few ways to protect yourself. Now, you can spread the information to your friends and family. Remember, only good hygiene habits protect you from being infected.

\section{REFERENCES}

1. Vyas, A., Kim, S. K., Giacomini, N., Boothroyd, J. C., and Sapolsky, R. M. 2007. Behavioral changes induced by Toxoplasma infection of rodents are highly specific to aversion of cat odors. Proc. Natl. Acad. Sci. U.S.A. 104:6442-7. doi: 10.1073/pnas.0608310104

2. Flegr, J., Prandota, J., Sovičková, M., and Israili, Z. H. 2014. Toxoplasmosis-a global threat. Correlation of latent toxoplasmosis with specific disease burden in 
a set of 88 countries. PLOS ONE 9:e90203. doi: 10.1371/journal.pone.0090203

3. Dubey, J. P., Lago, E. G., Gennari, S. M., Su, C., and Jones, J. L. 2012.

Toxoplasmosis in humans and animals in Brazil: high prevalence, high burden of disease, and epidemiology. Parasitology 139:1375-424. doi: 10.1017/S003118 2012000765

4. Arling, T. A., Yolken, R. H., Lapidus, M., Langenberg, P., Dickerson, F. B., Zimmerman, S. A., et al. 2009. Toxoplasma gondii antibody titers and history of suicide attempts in patients with recurrent mood disorders. J. Nerv. Ment. Dis. 197:905-8. doi: 10.1097/NMD.0b013e3181c29a23

5. Johnson, S. K., Fitza, M. A., Lerner, D. A., Calhoun, D. M., Beldon, M. A., Chan, E. T., et al. Risky business: linking Toxoplasma gondii infection and entrepreneurship behaviours across individuals and countries. Proc. R. Soc. Lond. B Biol. Sci. 285:20180822. doi: 10.1098/rspb.2018.0822

6. Zhang, N. Z., Chen, J., Wang, M., Petersen, E., and Zhu, X. Q. 2013. Vaccines against Toxoplasma gondii: new developments and perspectives. Expert Rev. Vaccines 12:1287-99. doi: 10.1586/14760584.2013.844652

7. Pinzan, C. F., Sardinha-Silva, A., Almeida, F., Lai, L., Lopes, C. D., Lourenço, E. V., et al. 2015. Vaccination with recombinant microneme proteins confers protection against experimental toxoplasmosis in mice. PLOS ONE 10:e0143087. doi: 10.1371/journal.pone.0143087

SUBMITTED: 08 October 2019; ACCEPTED: 10 March 2020; PUBLISHED ONLINE: 31 March 2020.

EDITED BY: Valerie Gerriets, California Northstate University, United States

CITATION: Mendonça-Natividade FC and Ricci-Azevedo R (2020) Toxoplasma gondii: A Microbe That Turns Mice Into Zombies. Front. Young Minds 8:36. doi: 10. 3389/frym.2020.00036

CONFLICT OF INTEREST: The authors declare that the research was conducted in the absence of any commercial or financial relationships that could be construed as a potential conflict of interest.

COPYRIGHT @ 2020 Mendonça-Natividade and Ricci-Azevedo. This is an open-access article distributed under the terms of the Creative Commons Attribution License (CC BY). The use, distribution or reproduction in other forums is permitted, provided the original author(s) and the copyright owner(s) are credited and that the original publication in this journal is cited, in accordance with accepted academic practice. No use, distribution or reproduction is permitted which does not comply with these terms.

\section{YOUNG REVIEWERS}

\section{CLEVEDEN SECONDARY, AGE: 15}

We are a higher biology class from Cleveden Secondary School in Glasgow. 


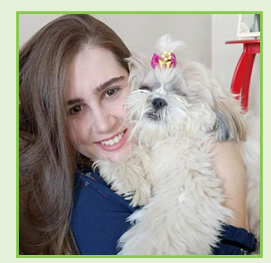

\section{AUTHORS}

\section{FLÁVIA COSTA MENDONÇA-NATIVIDADE}

Flávia is a Biochemist currently working as a Post-doc at the University of Sao Paulo, in Brazil. She studies how lectins from Toxoplasma gondii recognize sugars on immune cells how it influences the course of infection. During Flávia's free time, she likes to read, watch TV shows, travel, and have fun with her two little dogs.

\section{RAFAEL RICCI-AZEVEDO}

Rafael is a Biologist currently working as a Post-doc at the University of Sao Paulo, in Brazil. Rafael is focusing on understanding how neutrophils (which are the first immune cells to respond to invaders) respond to lectins from pathogens and how this impacts the outcome of infection. Beyond his passion for science, Rafael likes to travel and photograph the beauty of nature. *rrazevedo@gmail.com 